\title{
The Journal of Membrane Biology in 2020
}

\author{
Alexey S. Ladokhin ${ }^{1}$ \\ Published online: 26 March 2020 \\ (c) Springer Science+Business Media, LLC, part of Springer Nature 2020
}

Dear Colleagues,

It has been a year since I accepted the honor and the responsibility of serving our scientific community as Editorin-Chief of the Journal of Membrane Biology. Today I would like to provide you with several recent updates as well as share my understanding of some of the challenges we face working as scientists during an information revolution.

No scientific journal can survive these days without the consistent and dedicated support of the community it serves. In order to build the trust of such a community, the Journal has to fulfill two main expectations: publish high-quality content and do so quickly. The Editorial team of the JMBi has focused on these requirements over the past year and I am happy to report that we have become more discriminating in terms of the quality and impact of the work we publish and we have substantially reduced the processing time of submitted manuscripts. Currently, the mean time between submission and review-based editorial decision is about 30 days, and our goal is to further reduce this to 3 weeks. Of course, we were only able to achieve this progress due to our dedicated team of Associate Editors and Section Head Editors. I would like to thank all of the members of the Editorial team for their hard work and for their creativity. As Editorin-Chief, I am making it my goal in the coming months to encourage the staff of Springer Publishing Company to join the Editorial team in these enhanced efforts. A successful business model for the twenty-first century requires decentralization and independent decision-making. It would be prudent for Springer to embrace this trend and dismantle an entrenched system in which routine matters have to be "escalated" up the chain of command, requiring weeks to elapse before they are resolved.

Starting with this issue, we are instituting a new section to the Journal of Membrane Biology, which will introduce

Alexey S. Ladokhin

aladokhin@kumc.edu

1 Department of Biochemistry and Molecular Biology, The University of Kansas Medical Center, Kansas City, KS 66160-7421, USA researchers of exceptional promise and accomplishment who have not yet reached a mid-career level. Our inaugural featured Up-and-Coming Scientist is Dr. Elena Lesca of the Swiss Federal Institute of Technology in Zurich. Her work on the structural and functional aspects of the G ProteinCoupled Receptor family will be presented by the Biophysics Section Head Editor, Dr. Ana-Nicoleta Bondar, who is also to be credited with suggesting this new feature aimed at promoting early-career scientists.

I am also happy to announce the two upcoming Special Issues for the year 2020. The first one, entitled " $\mathrm{Na} / \mathrm{K}$ ATPase ion transport and receptor mediated signaling pathways", will be supervised by two distinguished Guest Editors Dr. Gustavo Blanco of the University of Kansas Medical Center and Dr. Sandrine Pierre of Marshall University. Dr. Blanco's research is related to ion transport and signaling mechanisms of Na/K-ATPase in the kidney and male reproduction. Dr. Pierre focuses on exploring new treatments for heart attacks and other cardiovascular conditions by studying how the Na/K-ATPase regulates cardiac cell physiology in health and diseases. The second special issue will focus on molecular interplay at the membrane and its impact on cellular physiology and be edited by Dr. Durba Sengupta, from the CSIR-National Chemical Laboratory in Pune, India, who had recently joined our team as an Associate Editor in Biochemistry.

We are looking forward to receiving both original work and reviews for the upcoming special issues as well as for our regular sections of Biophysics, Biochemistry, Biotechnology and Engineering, and Cell Biology.

Alexey S. Ladokhin, Editor-in-Chief.

Publisher's Note Springer Nature remains neutral with regard to jurisdictional claims in published maps and institutional affiliations. 